\title{
Possibilidades de abordagem do tema do suicídio na Estratégia Saúde da Família
}

\author{
I ${ }^{1}$ Geovana da Silva Ferreira, ${ }^{2}$ Ananyr Porto Fajardo, ${ }^{3}$ Eliana Dable de Mello I
}

Resumo: O artigo apresenta um estudo que teve como objetivo geral conhecer como os profissionais de uma unidade de Estratégia Saúde da Família (ESF) lidam com as demandas relacionadas ao tema do suicídio. Trata-se de uma pesquisa qualitativa com abordagem interpretativa, mediante grupo focal narrativo, realizado com profissionais de uma unidade de ESF, no município de Porto Alegre/ RS. Foram identificadas as dificuldades que ocorrem no trabalho com o tema do suicídio, e os efeitos psíquicos que elas provocam nos trabalhadores. As dificuldades em relação ao trabalho incluem: as vulnerabilidades sociais do território, o tabu do suicídio, as dificuldades de manejo dessas demandas pelos profissionais e a insuficiência da rede de serviços. Os efeitos psíquicos identificados nos trabalhadores foram: sentimento de impotência, culpa e frustração, bem como estresse e sensação de sobrecarga de trabalho. As principais conclusōes incluem a potencialidade do trabalho em ESF para a prevenção do suicídio, a necessidade de fortalecimento da rede de serviços e a importância da qualificação e do apoio permanentes aos profissionais, buscando ofertar os recursos necessários ao enfrentamento das dificuldades relacionadas ao trabalho com essa temática.

> Palavras-chave: suicídio; Saúde Pública; Estratégia Saúde da Família; Saúde Coletiva.

\author{
1 Programa de Residência \\ Multidisciplinar em Saúde, Grupo \\ Hospitalar Conceição. Porto \\ Alegre-RS, Brasil (geovana_sf_@ \\ hotmail.com) \\ ORCID: 0000-0003-2493-226X. \\ 2 Gerência de Saúde Comunitária, \\ Grupo Hospitalar Conceição. \\ Porto Alegre-RS, Brasil \\ (aportofajardo@gmail.com). \\ ORCID: 0000-0002-5501-3795. \\ ${ }^{3}$ Serviço de Saúde Comunitária, \\ Grupo Hospitalar Conceição. \\ Porto Alegre-RS, Brasil \\ (elianamello3@gmail.com). \\ ORCID: 0000-0002-7984-4913.
}

Recebido em: 14/03/2019 Revisado em: 09/05/2019 Aprovado em: 25/06/2019 


\section{Introdução}

O tema do suicídio é considerado, atualmente, um problema de saúde pública e o crescimento do número de casos registrados tem sido foco de preocupação em âmbito mundial. Por ser um fenômeno complexo e multifatorial que pode ser investigado a partir de vários aspectos, o suicídio como conceito da saúde é definido como "um ato deliberado, iniciado e levado a cabo por uma pessoa com pleno conhecimento ou expectativa de um resultado fatal” (WHO, 2002, p. 80).

Segundo a Organização Mundial da Saúde (OMS), mais de 800.000 pessoas morrem no mundo por suicídio a cada ano, e é a segunda causa de morte entre jovens de 15 a 29 anos de idade (WHO, 2014). Essas estimativas podem ser ainda maiores se for levado em conta que há subnotificação dos casos, seja devido a fragilidades nos sistemas de vigilância que os notificam como mortes acidentais ou causas desconhecidas, seja devido aos preconceitos ligados ao tema em diferentes contextos sociais e culturais (WHO, 2014).

No Brasil, as tentativas de suicídio estão entre os agravos de notificação compulsória e imediata em todo o território nacional (BRASIL, 2016). Observa-se um crescimento nos registros de óbitos por suicídio no país, o coeficiente de mortalidade por suicídio passou de 5,3 óbitos por 100.000 habitantes em 2011 para 6,5 em 2016 (BRASIL, 2017a; WHO, 2018). Este coeficiente corresponde à média nacional, embora haja variaçôes em relação às médias regionais. $\mathrm{Na}$ Região Sul, que tem as taxas mais elevadas do país em mortalidade por suicídio, o Rio Grande do Sul apresenta a maior média regional, a taxa de óbitos por esta causa em 2016 foi de 11,0 por 100.000 habitantes (RIO GRANDE DO SUL, 2018), quase o dobro da média nacional.

Diante deste cenário, em 2013 a OMS lançou seu Plano de Ação em Saúde Mental 2013-2020, no qual estabelece o objetivo de reduzir em 10\% a taxa global de suicídios até 2020 (WHO, 2013). O Brasil é signatário deste plano e, em setembro de 2017, o Ministério da Saúde publicou sua Agenda de Açóes Estratégicas para a Vigilância e Prevenção do Suicídio e Promoção da Saúde no Brasil 2017-2020. Entre os objetivos citados neste documento, consta a elaboração do Plano Nacional de Prevenção do Suicídio e ações em conjunto com as demais esferas da gestão e diversos setores governamentais e da sociedade civil (BRASIL, 2017b).

Pensar em prevenção do suicídio no âmbito da saúde pública implica pensar sobre a atuação na Atenção Primária em Saúde (APS). Ao considerar o papel da APS como 
porta de entrada e coordenadora do cuidado no Sistema Único de Saúde (SUS), ressalta-se a importância do trabalho neste ponto da rede, uma vez que o acesso ao atendimento de saúde para pessoas cuja demanda se relaciona de alguma forma com o tema do suicídio é base para a prevenção. Segundo o Ministério da Saúde, a Estratégia Saúde da Família (ESF) é a tática prioritária nacional de qualificação da APS (BRASIL, 2017c). Dessa forma, o trabalho dos profissionais na ESF pode ser visto como um elo fundamental desta rede de atenção em saúde.

Lidar com as demandas que envolvem o tema do suicídio pode representar angústia aos profissionais de saúde, pois muitas vezes são situações de difícil manejo e para as quais alguns profissionais não se sentem preparados. Falar sobre este tema mobiliza muitas emoçôes no ser humano e trabalhar com esta demanda também irá despertar afetos variados. Alguns estudos afirmaram o quanto o tema do suicídio pode despertar reaçôes negativas, como medo, agressividade e preconceitos (CASSORLA, 1991; RAPELI; CAIS; BOTEGA 2004; BOTEGA, 2015; OLIVEIRA et al., 2016). Além disso, o preparo do profissional é outro importante marcador na forma como se abordará o tema do suicídio. Algumas pesquisas mais recentes apontam que existe uma lacuna na formação dos profissionais de saúde em relação ao tema (RAMOS; FALCÃO, 2011; OLIVEIRA et al., 2016). Entretanto, na busca realizada, não foi encontrado material com investigaçóes a respeito de como essas questôes aparecem no trabalho fora de ambientes hospitalares, ou de equipes específicas de saúde mental. Este artigo visa contribuir nessa investigação ao tomar a APS como foco de estudo.

Ao ser levado em conta o papel da prevenção na APS e as dificuldades em trabalhar com essa temática, verificou-se a necessidade de conhecer como os profissionais de uma unidade de ESF localizada na capital do Rio Grande do Sul, Brasil, lidam com as demandas que envolvem o tema do suicídio. Com este intuito, lançou-se mão de uma pesquisa qualitativa de abordagem interpretativa para propiciar o aprofundamento da compreensão das possibilidades de abordagem do tema como problema de saúde pública. Ainda, buscou-se registrar reflexôes ampliadas sobre o contexto do trabalho em APS, pois, para além de metas de redução do suicídio, pensar em prevenção implica compreender melhor a realidade em que esse fenômeno ocorre.

\section{Metodologia}

O estudo foi realizado com base em uma pesquisa qualitativa de abordagem interpretativa com o objetivo de construir uma narrativa a partir de estratégias 
participativas. Os dados foram resultados de dois encontros no formato de grupo focal com desenho participativo, gravados em áudio mediante a aprovação dos participantes e transcritos na íntegra a seguir. $\mathrm{O}$ material final, composto pela narrativa e pelos resultados da análise dos dados, foi ainda apresentado para o grupo em um terceiro encontro. Todas estas etapas ocorreram entre maio e setembro de 2018.

A pesquisa foi realizada por duas psicólogas e uma odontóloga. A coleta de dados foi conduzida pela pesquisadora principal, que embasou o trabalho em estudo intensivo sobre a metodologia escolhida, a qual já havia sido utilizada por uma das coautoras. Participaram do estudo profissionais de uma unidade de ESF do município de Porto Alegre, Rio Grande do Sul, Brasil. O primeiro encontro em grupo focal ocorreu após a apresentação do projeto pela pesquisadora principal para todos os integrantes da unidade, e foi realizado com aqueles que manifestaram interesse pela pesquisa. Formaram o grupo duas médicas, uma enfermeira, uma técnica de enfermagem e quatro agentes comunitários de saúde, em um total de oito pessoas - sete mulheres e um homem, com idade entre 25 e 61 anos. Embora não tenha sido questionado o tempo de trabalho de cada profissional na ESF, três dos participantes o mencionaram espontaneamente: 4 meses, 5 meses, e 14 anos.

A metodologia do grupo focal com desenho participativo se divide em dois momentos (CAMPOS, 2011). O primeiro momento, correspondente ao primeiro encontro, é denominado grupo focal de discussão. Nesse encontro, a discussão partiu de questóes norteadoras e abertas da pesquisadora principal e foi encerrado por saturação teórica, ou seja, quando foi obtido material suficientemente denso para a primeira análise.

A seguir, ocorreu o processo de análise dos dados obtidos. O método utilizado para análise e interpretação dos dados foi uma construçáo narrativa a partir da transcrição das falas gravadas em áudio. A narrativa como texto coletivo consiste em uma forma de registrar organizadamente o material, de maneira a transformálo em um enredo do que foi trabalhado no grupo, considerada "uma estratégia de tornar denso o material, mantendo-se fiel a história que nele se conta, mas não necessariamente em sua sequência temporal e tampouco reproduzindo as formas lexicais do grupo" (CAMPOS, 2011, p. 1273).

Esta narrativa construída na primeira etapa da análise dos dados foi apresentada ao grupo no segundo momento, que corresponde ao segundo encontro, denominado 
grupo hermenêutico. Esse momento teve o papel de validar os dados apresentados na primeira narrativa e de produzir efeitos de aprofundamento das questóes pouco desenvolvidas no primeiro encontro. Após esse segundo momento, foi realizada a segunda etapa de análise dos dados a partir da codificação do material organizado como narrativa e validado pelos participantes em núcleos argumentais:

Um núcleo argumental é um conjunto de frases que não somente se referem a um tema,
também tenta atribuir a ele algum tipo de explicaçáo. Explicaçáo no sentido de um por-
quê, de um para quê e de um como. Os núcleos argumentais não são os temas levantados,
porém a "tessitura da intriga" sobre esses temas (CAMPOS, 2011, p. 1278).

Dessa forma, a narrativa final consistiu em um texto que contemplou a diversidade de explicaçóes e posicionamentos, além dos diferentes argumentos do grupo sobre o tema pesquisado. $\mathrm{O}$ texto final tem o efeito de qualificação do material colhido e de implicação e envolvimento de todos participantes da pesquisa (CAMPOS, 2011). Tais efeitos são devidos ao fenômeno do texto como uma escrita que permite que seus autores se apropriem do que ali está exposto, proporcionando uma mediação simbólica entre discurso e ação (RICOEUR, 1997), o que resulta em uma construção que inscreve a experiência do trabalho produzido no campo intelectual-científico e social.

A escolha dessa técnica de coleta de dados se deu pelo fato de que o suicídio é um tema difícil de ser abordado, e seria mais bem desenvolvido em grupo. Além disso, o desenho participativo do grupo focal narrativo possibilita experimentar uma modalidade de pesquisa-intervençâo, na qual as narrativas produzidas "atenderiam a um pouco do nosso imperativo ético-político, intervindo no universo pesquisado, propiciando fortalecimento de seus próprios agentes" (CAMPOS; FURTADO, 2008, p. 333). Dessa forma, os efeitos das narrativas sáo proporcionar aos participantes da pesquisa uma importante reflexão acerca do tema, a partir do contato com o material produzido e sua apropriação interpretativa.

Esta pesquisa foi avaliada e aprovada pelo Comitê de Ética em Pesquisa do Hospital Nossa Senhora da Conceição do Grupo Hospitalar Conceição (CEP/ GHC), sob o parecer no 2.407.070, e pelo Comitê de Ética em Pesquisa da Secretaria Municipal de Saúde de Porto Alegre (CEP/SMSPA), sob o parecer no 2.471.952, e cumpriu as recomendaçôes da Resolução no 466/2012 do Conselho Nacional de Saúde (BRASIL, 2012). 


\section{Resultados e Discussão}

No primeiro encontro, a discussão do grupo teve início com a questão colocada pela pesquisadora principal sobre como acontece o acolhimento dos pacientes que trazem o suicídio como tema de preocupação. A partir do desenvolvimento da discussão, a pesquisadora questionou também acerca das características do território adscrito da unidade e sobre os sentimentos dos profissionais frente ao trabalho com essa demanda.

A análise da narrativa produzida resultou na identificaçáo de dificuldades que o grupo encontra em relação ao trabalho com o tema do suicídio e de efeitos psíquicos que essas dificuldades provocam nos profissionais. Seráo apresentados aqui alguns dos núcleos argumentais que compóem a narrativa final validada pelos participantes e que descrevem tais dificuldades e efeitos psíquicos. Cabe ressaltar que a narrativa é um texto que representa o grupo e não cada profissional de forma individual. Sua construção é na primeira pessoa do plural, e a versão final é entregue aos profissionais como um produto que pertence ao grupo. Portanto, o que será apresentado neste artigo são trechos desse produto final, com as respectivas análises e interpretações.

\section{Vulnerabilidades Sociais}

A territorialização e a população adscrita estão entre as diretrizes para a operacionalização do trabalho em APS, sendo que as ações em saúde nesse nível de atenção terão como foco o território como espaço geográfico onde se desenvolvem os condicionantes e determinantes de saúde daquela população específica que o constitui (BRASIL, 2017c). Ao levar isso em conta, o entendimento de como se estabelecem as relaçôes de vínculo de uma equipe de Saúde da Família (eSF) com os seus usuários perpassa a compreensão desse território.

A unidade de saúde que foi cenário da pesquisa está localizada em um território caracterizado pela existência de riscos e vulnerabilidades sociais e é um dos principais recursos acessíveis à população de baixa renda que ali reside. A população adscrita é de aproximadamente 5.300 pessoas, que estão sob responsabilidade de duas eSF que atuam no local. Em relação às condiçôes de vida de seus usuários, os profissionais destacam as fragilidades existentes:

Trabalhamos com uma outra realidade, num território com violências, tráfico, falta de saneamento básico. Atendemos pessoas que não têm banheiro, que não têm o que dar para os filhos, que conseguem dormir porque tomam medicamentos, mas que ao acordar se deparam com a mesma coisa: chove dentro de casa, pisam em cima do barro, sentem o cheiro do bueiro que medicaçáo nenhuma vai mudar. 
É possível observar que a preocupação do grupo com essas condiçôes de vida está relacionada com o conceito de determinantes sociais da saúde, que são definidos pela Comissão Nacional sobre os Determinantes Sociais da Saúde (CNDSS) como "fatores sociais, econômicos, culturais, étnicos/raciais, psicológicos e comportamentais que influenciam a ocorrência de problemas de saúde e seus fatores de risco na população" (BUSS; PELLEGRINI FILHO, 2007, p. 78). Ao falar sobre tais fragilidades existentes, os profissionais as apresentam como dificuldades que muitas vezes limitam suas açôes, uma vez que as necessidades dos usuários ultrapassam a capacidade de oferta das equipes, como pode ser observado no seguinte núcleo argumental:

Lidamos com um problema social que parece que não vamos resolver aqui nunca, porque a resolução não é questão da doença, é uma questâo sociocultural.

Apesar de haver uma compreensão sobre a influência das vulnerabilidades sociais na saúde da população, os profissionais ainda se percebem como limitados para lidar com os aspectos relacionados apenas à doença em si mesma, sem conseguir ir além na articulação de possibilidades de atuação sobre o contexto em que a pessoa doente está inserida. Quando abordam o tema da saúde mental, também relacionam essa demanda à existência dessas vulnerabilidades:

E a nossa população tem uma demanda de saúde mental muito grande. [...] Quando falam, nos sugam, são muitos problemas juntos. São situaçôes de vida que passaram e que não vão mudar mais, maus-tratos, abusos, vulnerabilidades sociais. A maioria não tem círculo social nem rede de apoio.

Neste núcleo argumental também fica evidente o fator da fragilidade da rede comunitária do território. Ainda dentro do modelo de compreensão dos determinantes sociais de saúde, é possível afirmar que "os laços de coesão social e as relaçôes de solidariedade e confiança entre pessoas e grupos são fundamentais para a promoção e proteção da saúde individual e coletiva" (BUSS; PELLEGRINI FILHO, 2007, p. 86). Diante disso, os profissionais de saúde aparecem muitas vezes como o único apoio possível para essa população, que lhes demanda uma atenção ampla e de cuidados diversos.

\section{Suicídio como tabu}

A percepção do suicídio como um fenômeno complexo e multifatorial, e como problema de saúde pública, como é concebido atualmente, é uma compreensão 
construída ao longo do tempo. É um fenômeno presente desde a Antiguidade, que teve suas significaçóes transformadas conforme o contexto cultural e social em que se inseria, e conforme os avanços do estudo científico acerca do assunto em diferentes épocas. Durante a Idade Média, foi considerado um ato proibido, julgado pela Igreja como um pecado e pelo Estado como um crime. Ao final desse período, com a inserção do poder da medicina na sociedade, o início do interesse científico em torno das chamadas "mortes voluntárias" ainda carregava o tema de um valor negativo, pois o qualificava como loucura (NETTO, 2013, p.16).

Apesar dos avanços em relação ao estudo e compreensão do suicídio, as concepções construídas anteriormente até hoje ainda conferem um status de tabu a esse tema. Em relação a isso, os profissionais da unidade de saúde pesquisada apontam a dificuldade que os pacientes apresentam em falar sobre esse sofrimento:

Temos alguns que se reportam mais para os agentes comunitários de saúde do que para demais profissionais, talvez por conta do constrangimento. [...] São pacientes bem preocupantes e a maioria não fala diretamente, só quem está necessitado mesmo que chega trazendo a ideação como problema principal.

É possível identificar também neste núcleo argumental uma importante potencialidade da abordagem do tema suicídio na APS, que é a construção do vínculo com o paciente. $\mathrm{O}$ status de tabu conferido ao tema dificulta que se fale abertamente sobre isso, que se comunique a intenção e, junto com ela, todo o sofrimento do qual ela emerge e com o qual o paciente não mais consegue lidar sozinho. Portanto, é necessário existir uma relação de confiança que permita essa comunicação. Essa confiança pode ser encontrada na figura do agente comunitário de saúde, profissional com o qual geralmente há um vínculo maior pelo fato de pertencerem também àquele território. Ou ainda poderá ser uma confiança construída durante um atendimento, pela postura acolhedora de quaisquer dos profissionais que constituem uma eSF, abrindo um diálogo que demonstre o interesse pela vida do paciente como um sujeito biopsicossocial.

Uma vez estabelecido o vínculo com base em uma relação de confiança com o paciente, o profissional de eSF, ao se deparar com uma ideaçáo suicida, ainda encontra dificuldades para falar sobre o tema com a família:

Se decidimos por encaminhar para a emergência de saúde mental, ele não pode ir sozinho, e muitas vezes temos que contar com alguém da família que acha que é frescura. [...] Alguns familiares ficam bravos, não acreditam, temos que assustar e impressionar para eles entenderem. 
Sobre a dificuldade de aceitação desse tipo de sofrimento psíquico, a teoria psicanalítica traz algumas contribuiçóes (NETTO, 2013; CARLOS, 2014). Ao ser tomado como tabu, o suicídio, além de remeter a esse passado de crime e pecado do ato, remete também à própria dificuldade de falar da morte, seja uma morte de si mesmo ou a morte de outros. Há algo de irrepresentável na morte, independente da causa, que provoca dificuldades para encontrar palavras com as quais falar dela. Quando essa morte é por suicídio, a dificuldade se acentua, o que segundo Carlos (2014, p. 53) parece apontar um lugar de obsceno a esse ato, uma vez que convoca o olhar ao mesmo tempo que o rechaça, devido à impossibilidade de o sujeito dar conta do que ali se presentifica.

Este lugar obsceno que o suicídio ocupa na sociedade faz com que muitas vezes não seja possível chegar antes de o ato acontecer. Tanto essa dificuldade, que resulta em um esforço inconsciente para não ver o sofrimento psíquico em causa, quanto todo o preconceito em torno do tema estão relacionados aos casos que não chegaram para atendimento na unidade pesquisada, mas que também são citados pelos profissionais:

Tivemos casos em que se suicidaram e ninguém tinha percebido que estavam com sérios problemas. E outros casos em que os familiares não vieram procurar, não quiseram ajuda, não quiseram se expor, por causa do estigma.

Este núcleo argumental evidencia a dificuldade de prevenção ligada ao status de tabu do tema do suicídio na sociedade. Dessa forma, os profissionais também encontram um obstáculo à sua atuação diante desse aspecto negativo de compreensão do tema, ainda muito presente no contexto sociocultural atual, sendo necessário desmistificar o suicídio para poder intervir de forma mais efetiva.

\section{Dificuldades de Manejo pelos profissionais}

Ao identificar um caso no território que envolva o tema do suicídio, os profissionais relatam a existência de determinados fluxos internos para a abordagem, como: intervenção do agente comunitário de saúde junto à família, discussão do caso na equipe e instrumentos de avaliação do risco suicida na consulta, entre outros. Contudo, foram identificadas também algumas dificuldades desses profissionais no manejo da demanda em torno do tema do suicídio.

Entre essas dificuldades, está o fato de que a unidade é a principal referência para sua população, como discutido anteriormente, pois não existem outros dispositivos 
de apoio no território. Nesse sentido, os profissionais relatam suas fragilidades em dar conta dessa demanda que às vezes parece vir em excesso:

Fazemos um trabalho de formiga, muito pequeno, e somos muito cobrados pelos pacientes. Porque somos o que eles têm mais perto, onde eles encontram acesso mais rápido. [...] A demanda é muito grande, a maior parte das nossas agendas é de casos de saúde mental, e em casos assim as consultas podem durar até 3 horas, ficamos no mínimo 25 minutos conversando até surgir a questão da ideação para avaliação.

Essa percepção de excesso, em casos que envolvem o tema do suicídio, não está ligada apenas à noção de quantidade, mas também se relaciona ao conteúdo desses atendimentos, como exemplificado pela questão da duração dessas consultas. Assim, ao se depararem com uma ideação suicida no atendimento, o restante da agenda será afetado, o tempo utilizado com aquele paciente exigirá uma reorganização do tempo que será destinado aos demais. Com isso, vem a sensação de ter um "trabalho de formiguinha" diante da imensidáo das demandas.

Os profissionais relatam ainda não se sentirem totalmente preparados para o atendimento desses casos, devido à ausência de capacitação específica para atuarem neste problema:

Nos sentimos capacitados para acompanhar, não para nos responsabilizarmos totalmente.

Diante da ausência de capacitação, surge um embaraço nos profissionais em identificar o que é possível ser feito no manejo desses casos dentro da unidade. Em certos casos, a medicalização aparece como uma possibilidade, porém os profissionais também compreendem a ineficácia ou insuficiência dessa terapêutica:

Temos pacientes que imploram ajuda, mas que não temos o que fazer, porque são problemas que não podemos ir além, que a fluoxetina e a amitriptilina vão dar uma aliviada, mas depois a crise vai voltar, os problemas váo continuar. Nos sentimos tapando buraco com medicaçáo, tirando a parte aguda para os pacientes continuarem vivos.

O tema do suicídio, assim como os casos com problemáticas de saúde mental em geral, colocam os profissionais frente ao inusitado, àquilo que não está objetivado nos protocolos existentes, a fatores que não respondem diretamente a técnicas utilizadas para o tratamento de outras doenças específicas. O fazer prático ao qual estão familiarizados parece não ter mais efeito perante essa demanda:

Tem casos que não fazemos a menor ideia de por onde começar, outros que não sabemos mais o que falar para eles, que não temos capacidade de oferecer o que precisam. 
Esta sensação de incapacidade pode advir de uma falta de conhecimentos aprofundados sobre o manejo de casos que envolvam o tema do suicídio. A ideia de que o profissional precisa fazer ou falar algo se sobrepóe à possibilidade de apenas escutar de forma acolhedora. Ao tomar a demanda como problemas dos quais se infere quais são as soluçôes, e que essas soluçôes são o que o paciente precisa, o profissional entra em um tipo de imobilidade por não poder oferecer o que se imagina ser necessário. Entretanto, talvez não se tenha conseguido compreender o que, de fato, o paciente precisa naquele momento. Em situaçôes de crise, muitas vezes a escuta de um profissional pode ser o bastante, pois há um valor terapêutico em deixar que o paciente se expresse livremente (BOTEGA, 2015, p. 183).

Dessa forma, é possível perceber certo nível de despreparo dos profissionais sobre possibilidades de manejo da demanda relacionada com o tema do suicídio na APS, pois fica evidente a falta de formação específica sobre o assunto, tanto anterior à entrada no trabalho quanto também à ausência de ações de educação permanente no próprio serviço.

\section{Insuficiência da rede}

Após o caso ser acolhido na unidade, os profissionais podem dispor dos outros serviços da Rede de Atenção Psicossocial (RAPS) do município, os quais podem ser acessados para encaminhamentos e compartilhamento do caso, conforme a complexidade do quadro. Entretanto, foram relatados diversos impasses que surgem nas tentativas de acesso aos pontos de atenção desta rede.

Com uma população estimada de 1.479 .101 habitantes (IBGE, 2018) e 53,1\% de cobertura populacional de ESF, o município conta com nove Núcleos de Apoio à Saúde da Família (NASF) (PORTO ALEGRE, 2017). Além de serem insuficientes, nem todas as equipes estão completas. No período de realização deste estudo, a equipe do NASF responsável pela unidade pesquisada alterou a forma de realização do matriciamento devido ao número insuficiente de profissionais, restringindo à especialidade de psiquiatria a oferta para aquele território, uma vez que a demanda dessa ESF ao NASF se concentrava na maior parte em casos de saúde mental. Apesar de ter esse matriciamento, os profissionais da ESF percebem que ele não ocorre de forma adequada:

O matriciamento com psiquiatra do NASF demora muito para acontecer, se a gente for esperar para matriciar com o NASF, o paciente talvez não chegue nas próximas duas 
semanas. [...] $\mathrm{O}$ acesso aos especialistas tem sempre demora, porque são poucos profissionais para uma demanda que cada vez aumenta mais.

Além da diferença entre a quantidade de oferta e de demanda, o que provoca a demora no acesso, a qualidade deste serviço também foi questionada pelos profissionais, uma vez que se torna difícil realizar de forma eficiente o que se propóe adiante da sobrecarga de trabalho. No período da pesquisa, o NASF não contava com profissionais da psicologia e serviço social, embora houvesse demanda para estas especialidades:

Alguns pacientes conseguem acessar o psiquiatra, mas também precisam de psicoterapia, e o psiquiatra náo vai fazer psicoterapia porque a consulta é rápida e muitas vezes sem continuidade. [...] Além da psicoterapia, temos questóes que precisaria de assistência social, que há dificuldade de acesso também.

Ao falar sobre a demanda para a assistência social, retoma-se as questóes referentes ao contexto de vulnerabilidade social do território adscrito à unidade. Este contexto dificulta o acesso a outros pontos de atenção da rede, como em casos em que é preciso que o paciente se desloque de ônibus para determinados serviços. Como exemplo, os profissionais citam os serviços de Plantôes de Emergência em Saúde Mental, até mesmo o mais próximo do território está a uma distância em que o paciente precisa ir de ônibus. Dessa forma, quando um paciente avaliado com alto risco de suicídio é acolhido na unidade, a espera pelo matriciamento não é adequada, pois é necessário um atendimento mais específico. Contudo, o encaminhamento para essa emergência nem sempre se cumpre:

Isso quando conseguem ir até a emergência, porque às vezes eles não têm quem chamar para acompanhar, ou não têm passagem para ir, e o SAMU [Serviço de Atendimento Móvel de Urgência] não vem para esses casos.

Em relação aos casos que necessitam de acompanhamento especializado mais contínuo, os serviços acessados seriam os Centros de Atenção Psicossocial (CAPS). O município de Porto Alegre conta com 12 CAPS: três CAPSi, quatro CAPS II, três CAPS AD III e dois CAPS AD (PORTO ALEGRE, 2017). Ao cotejar com a abrangência populacional do município, o número desses serviços também é inadequado às necessidades, como evidenciado no seguinte núcleo argumental:

É muito complicado os acessos aos CAPS também, quase impossível conseguirmos uma vaga, eles não conseguem dar conta de uma demanda que é maior do que a capacidade deles. [...] É ínfimo o número de pacientes que apresentam bons resultados, pouquíssimos conseguem um bom vínculo com algum serviço de saúde mental. 
Frente aos impasses relatados, que dificultam a vinculação e limitam o acesso aos demais serviços da RAPS, o cuidado no território de responsabilidade da ESF se torna o principal, ou até mesmo o único possível.

\section{Efeitos psíquicos}

Daí vêm os sentimentos de impotência, de frustração, com uma carga de estresse que é muito grande. Não é só a saúde mental da população que está em foco, é a saúde mental nossa também, a de trabalhadores, que está muito prejudicada.

O núcleo argumental acima traz um elemento transversal a todos os itens descritos anteriormente, que são os sentimentos e percepçôes dos profissionais frente ao trabalho com a demanda que envolve o tema do suicídio. Para além das dificuldades intrínsecas ao assunto, exemplificadas no item "Suicídio como tabu", foram relatadas também dificuldades ligadas às características do contexto em que se desenvolve o trabalho da unidade pesquisada, de forma que a relação entre todos esses impasses provoca efeitos psíquicos nesses profissionais.

Reconhecida a importância do trabalho da APS na prevenção do suicídio e na atenção ao paciente em crise, é indispensável considerar também se os atores desse trabalho dispóem dos recursos necessários, tanto internos quanto externos, para desenvolver suas funçôes de maneira adequada. Sobre as condiçóes em que se desenvolve o trabalho, os profissionais relatam que:

[...] são muitos casos difíceis, que fazem com que o número pequeno que temos aqui nos estressem mais do que 30 em outros lugares com outras condiçóes.

Esta sensação de sobrecarga de trabalho remete aos recursos externos, como uma rede de serviços com a qual os profissionais pudessem compartilhar os casos, ou um território com fatores que promovessem maior proteção a sua população. $\mathrm{Na}$ inexistência dessas condiçóes, os casos parecem tomar proporçóes maiores do que os limites suportados pelos profissionais. Dessa forma, os recursos internos, que seriam as capacidades técnicas e pessoais, também parecem ser insuficientes:

Chega um estágio que não temos mais estrutura para eles. São casos muito complexos, com motivos que também nos fariam ficar deprimidos, com resultados que não vão ser o que gostaríamos, coisas que vão além do que a gente consegue fazer.

Neste núcleo argumental é possível observar o processo de identificação que pode ocorrer na relação do profissional com o paciente. $\mathrm{Na}$ teoria psicanalítica, o suicídio é tido como um ato em que o sujeito volta para si mesmo a agressividade que não 
consegue descarregar em objetos externos (ROUDINESCO; PLON, 1998). Dessa forma, os profissionais podem sentir-se identificados com estes objetos originalmente atacados pelo ato suicida. Conforme Cassorla (1991, p. 153), o profissional será invadido inconscientemente por sentimentos de impotência, frustração e fragilidade que o paralisam diante da violência de ordem emocional do paciente.

Seria necessário que este processo inconsciente pudesse ser percebido de forma consciente pelos profissionais; por exemplo, por meio de discussôes do caso com outros colegas, para que então alguma ação mais consciente pudesse emergir desses sentimentos negativos. A culpa foi outro sentimento que apareceu nesse tema, conforme o seguinte núcleo argumental:

Nos sentimos ultrapassados, e até mesmo culpados porque temos o que eles não têm [...] parece que não estamos resolvendo a qualidade de vida das pessoas, náo estamos fazendo diferença aqui. [...] A gente faz tudo e nos sentimos como se não tivéssemos feito nada.

Este sentimento de culpa, acompanhado pela percepção de impotência, é um fator muito presente no trabalho com o tema do suicídio. A angústia que leva o profissional a acreditar que é preciso agir, que é preciso resolver a vida do paciente ou sentir-se responsável por ela, com base no medo de que o paciente venha a se matar, poderá bloquear a capacidade de lidar melhor com essas situaçôes. É necessário perceber que ser responsável pelo tratamento é diferente de ser responsável pela vida do paciente, e que é possível que o profissional se sinta mais seguro na medida em que aceita que seu paciente poderá vir a se matar, apesar de todos os esforços empreendidos (BOTEGA, 2015, p. 207).

Contudo, para que esse processo de reflexão sobre o acompanhamento dos casos ocorra, é preciso que exista um espaço de fala e apoio dos profissionais, o que não é a realidade da ESF pesquisada, conforme aparece no seguinte núcleo argumental:

Não temos uma rede de apoio. Alguns de nós começaram a tomar remédio também, outros criaram um bloqueio para não sugar e carregar tanta coisa, e outros ainda carregam. Tem coisa que vamos aprendendo com o tempo, aprendendo a separar, mas tem coisa que ficamos impressionados mesmo.

Como afirmado anteriormente, é necessário perceber alguns processos e sentimentos inconscientes para conseguir pensar e tomar decisóes de forma mais calma e clara. Entretanto, como fazer isso sem uma rede de apoio, sem espaços para falar e refletir sobre esses impasses? Essa dificuldade de separar o que é de si e o que é da relação com o paciente provoca sofrimento: 
Esse é um aspecto específico das profissões da área da saúde: a reparação tem de ser feita tấo concretamente, sobre seres humanos táo semelhantes aos cuidadores, de tal modo que deixa vulnerável quem a exerce. Para poder trabalhar de modo adequado, sem sobrecarga de tensão, onipotência ou culpa, deve-se adquirir maturidade e capacidade para aceitar as limitaçóes impostas pela realidade (BOTEGA, 2015, p. 207).

$\mathrm{Na}$ ausência de uma rede de apoio, os efeitos psíquicos aparecem, assim como as estratégias individuais para amenizar as angústias, como a medicação ou a criação de bloqueios emocionais, isto é, passa-se a reprimir e negar os sentimentos com os quais náo se consegue lidar. A capacidade de lidar com as limitaçóes da realidade deve surgir à medida que forem constituídos espaços para se refletir sobre ela de forma consciente e madura e, a partir deste processo reflexivo, construir os recursos necessários para transformá-la. As discussóes do grupo provocaram isso, conforme mostra o seguinte núcleo argumental:

Talvez a gente tenha que criar um NASF só para nós, ou um grupo de autoajuda, de psicoterapia. Porque são coisas que se a gente guardar, vão ficar doentes na gente.

Isso ilustra também que a análise da realidade investigada foi construída com os profissionais a partir dos efeitos da narratividade (CAMPOS, 2011), na interação entre a pesquisadora principal e os participantes do grupo. Ao conseguirem expor suas angústias e compartilhar suas percepçôes no grupo, eles também vislumbraram possíveis soluçóes.

Ao levar em conta tais resultados, é possível sugerir que o investimento em educação permanente para os trabalhadores da saúde pode contribuir para aprimorar as açóes junto a essa realidade. A inclusão periódica do tema do suicídio no calendário de reuniôes das equipes, com a presença de outros profissionais convidados apropriados do assunto, e a viabilização de capacitaçóes externas com temáticas da saúde mental, são exemplos de como esse investimento pode ocorrer. Outra necessidade é o fortalecimento da rede a partir da ampliação de serviços que estejam em número insuficiente à demanda, e da qualificação do trabalho naqueles já existentes. Para isso, é preciso que atores da gestão nos diversos níveis da rede intersetorial estejam envolvidos e corresponsabilizados pela discussão e implementação das melhorias imprescindíveis.

Em relação aos efeitos psíquicos observados nos relatos dos profissionais participantes da pesquisa, considera-se importante oportunizar encontros entre os profissionais das equipes de saúde para discussão de situaçóes de sofrimento causadas 
pelo trabalho. Poderiam ser incluídos no calendário de reunióes das equipes, com a presença de colegas vinculados à saúde do trabalhador. Desses espaços de fala e escuta dos profissionais pode decorrer a criação de alternativas, com base no que possa advir desses processos reflexivos, que busquem fortalecer a perspectiva do cuidado em saúde mental.

\section{Considerações finais}

Buscou-se neste estudo apresentar as possíveis formas de abordagem do tema do suicídio na APS, com base nas compreensóes dos profissionais de uma ESF sobre o trabalho com essa demanda. Como o tema é um problema de saúde pública, e é necessário preveni-lo, foi evidenciada a potencialidade deste trabalho na ESF por ser porta de entrada do sistema e coordenadora dos cuidados em saúde. Sob a perspectiva dos planos de redução das taxas de suicídio em âmbito nacional e mundial, objetivou-se ampliar a visão sobre a necessidade de estudo da questão para além das metas quantitativas. Nesse sentido, o uso de uma metodologia qualitativa, de abordagem interpretativa e participativa, permitiu contemplar a proposta de refletir ativamente com todos os atores sobre a realidade investigada.

Foram encontrados nos relatos dos profissionais pesquisados os diversos aspectos que constituem a complexidade do fenômeno suicídio e suas interfaces com o trabalho na ESF. Foi possível perceber as dificuldades que se apresentam no cotidiano desse trabalho e o quanto este contexto também afeta a saúde mental dos profissionais. Os resultados apresentados denotam a necessidade de fortalecimento das redes de saúde como um todo, devido às fragilidades dos profissionais e dos serviços, e ao fato de o suicídio ser um problema que demanda intervençôes interdisciplinares e intersetoriais.

Este fortalecimento deve incluir investimentos na efetivação de políticas públicas já existentes, como a RAPS e a Política Nacional de Atenção Básica (PNAB), cujos princípios e diretrizes corroboram a visão de uma atenção à saúde que considere o sujeito em sua integralidade. Além disso, a qualificação permanente nos serviços é indispensável para ofertar aos profissionais os recursos necessários para que possam lidar melhor com os impasses que surgem na abordagem do tema do suicídio, assim como a existência de espaços de diálogo entre profissionais e equipes, que possibilitem um apoio nas dificuldades, e uma atençáo maior à saúde mental desses trabalhadores.

Vale ressaltar ainda o caráter de pesquisa-intervenção deste estudo, uma vez que a metodologia utilizada proporcionou um espaço de reflexáo sobre o tema e uma 
apropriação do material produzido pelos participantes. Enquanto limitaçóes do estudo, é importante mencionar que o cronograma da pesquisa não permitia que a metodologia fosse aplicada com mais de um grupo. Entretanto, por se tratar de um estudo qualitativo, o número reduzido de participantes não desqualifica o material produzido, dado o aprofundamento na análise, apesar de admitir-se que uma maior diversidade de narrativas poderia enriquecer a discussão.

O suicídio é um fenômeno complexo e a diversidade das realidades de APS no país indicam que este estudo traz importantes contribuiçôes para a compreensão das abordagens do tema como problema de saúde pública. No entanto, outras e mais aprofundadas investigações são necessárias para ampliar as possibilidades de intervenção no contexto atual, no qual ainda é preciso lidar com o status de tabu do suicídio e com o constante risco de enfraquecimento das políticas públicas existentes, as quais deveriam auxiliar no enfrentamento dessa realidade. ${ }^{1}$

\section{Referências}

BOTEGA, N. J. Crise suicida: avaliação e manejo. Porto Alegre: Artmed, 2015.

BRASIL. Ministério da Saúde. Conselho Nacional de Saúde. Resoluçâo no 466, de 12 de dezembro de 2012. Diário Oficial da Uniāo, Brasília-DF, 2012.

. Gabinete do Ministro. Portaria no 204, de 17 de fevereiro de 2016. Define a Lista Nacional de Notificação Compulsória de doenças, agravos e eventos de saúde pública nos serviços de saúde públicos e privados em todo o território nacional, nos termos do anexo, e dá outras providências. Diário Oficial da Uniāo, Brasília-DF, 2016.

. Secretaria de Vigilância em Saúde. Boletim Epidemiológico. Brasília, v. 48, n. 30, 2017a.

- Secretaria de Atenção à Saúde. Departamento de Ações Programáticas Estratégicas. Agenda de Açôes Estratégicas para a Vigilância e Prevenção do Suicídio e Promoção da Saúde no Brasil: 2017 a 2020. Brasília: Ministério da Saúde, 2017b.

. Gabinete do Ministro. Portaria no 2.436, de 21 de setembro de 2017. Aprova a Política Nacional de Atençáo Básica, estabelecendo a revisão de diretrizes para a organizaçáo da Atençáo Básica, no âmbito do Sistema Único de Saúde (SUS). Diário Oficial da União, Brasília-DF, 2017c.

BUSS, P. M.; PELLEGRINI FILHO, A. A saúde e seus determinantes sociais. Physis. Rio de Janeiro, v. 17, n. 1, p. 7-93, abr. 2007. Disponível em: <http://www.scielo.br/scielo. php?pid=s0103-73312007000100006\&script=sci_abstract\&tlng=pt $>$. Acesso em: 20 nov. 2018. 
CAMPOS, R. O. Fale com eles! O trabalho interpretativo e a produção de consenso na pesquisa qualitativa em saúde: inovaçóes a partir de desenhos participativos. Physis. Rio de Janeiro, v. 21, n. 4, p. 1269-1286, out./dez. 2011. Disponível em: <http://www.scielo.br/scielo.php?script=sci_ arttext\&pid=S0103-73312011000400006>. Acesso em: 20 nov. 2018.

CAMPOS, R. O.; FURTADO, J. P.. Narrativas: Apontando alguns caminhos para sua utilização na pesquisa qualitativa em saúde. In: CAMPOS, R. O. et al. (Org.). Pesquisa Avaliativa em Saúde Mental: desenho participativo e efeitos da narratividade. Sáo Paulo: Aderaldo \& Rothschild, 2008.

CARLOS, F. P. de. O lugar obsceno do suicídio. 58 p. Dissertação (Mestrado em Psicologia Social e Institucional) - Universidade Federal do Rio Grande do Sul, Porto Alegre, 2014.

CASSORLA, R. M. S. O impacto dos atos suicidas no médico e na equipe de saúde. In: CASSORLA, R. M. S. Do Suicídio: Estudos Brasileiros. Campinas: Papirus, 1991, p. 149-165.

IBGE. Instituto Brasileiro de Geografia e Estatística. Estatísticas por Cidade e Estado. Rio de Janeiro, 2018. Disponível em: <https://www.ibge.gov.br/estatisticas-novoportal/por-cidadeestado-estatisticas.html?t=destaques\&c=4314902>. Acesso em: 1 dez. 2018.

NETTO, N. B.. Suicídio: uma questão de saúde pública e um desafio para a psicologia clínica: Parte I. In: CFP. Conselho Federal de Psicologia. O suicidio e os desafios para a psicologia. Brasília: CFP, 2013.

OLIVEIRA, C. T. de et al. Percepçôes de uma equipe de saúde mental sobre o comportamento suicida. Gerais: Revista Interinstitucional de Psicologia. Juiz de Fora, v. 9, n. 1, jun. 2016. Disponível em: <http://pepsic.bvsalud.org/scielo.php?script=sci_arttext\&pid=S198382202016000100007\&lng=pt\&nrm=iso\&tlng=pt>. Acesso em: 3 nov. 2018.

PORTO ALEGRE. Secretaria Municipal de Saúde. Plano Municipal de Saúde 2018-2021. Porto Alegre, 2017. Disponível em: <http://lproweb.procempa.com.br/pmpa/prefpoa/sms/usu_ doc/plano_municipal_de_saude_-_pms_2018-2021_-_revisado_em_16_01_18.pdf>. Acesso em: 1 dez. 2018.

RAMOS, I. N. B.; FALCÃO, E. B. M. Suicídio: um tema pouco conhecido na formaçáo médica. Revista Brasileira de Educação Médica, v. 35, n. 4, 2011. Disponível em: <http://www. scielo.br/pdf/rbem/v35n4/a10v35n4.pdf>. Acesso em: 3 nov. 2018.

RAPELI, C. B.; CAIS, C. F. da S.; BOTEGA, N. J. Comportamento suicida no hospital geral. In: WeRLANG, B. S. G.; BOTEGA, N. J. (Org). Comportamento Suicida. Porto Alegre: Artmed, 2004, p. 183-188.

RICOEUR, P. Tempo e narrativa. Tomo III. Trad. Roberto Leal Ferreira. Campinas: Papirus, 1997. RIO GRANDE DO SUL. Secretaria da Saúde. Centro Estadual de Vigilância em Saúde. Boletim de Vigilância Epidemiológica de Suicídio e Tentativa de Suicídio. Porto Alegre, v. 1, n. 1, 2018. 
ROUDINESCO, E.; PLON, M. Dicionário de Psicanálise. Trad. Vera Ribeiro e Lucy Magalhães. Rio de Janeiro: Zahar, 1998.

WORLD HEALTH ORGANiZATION. Relatório Mundial da Saúde: Saúde Mental. Trad. Gabinete de Tradução Climepsi Editores. Lisboa: Climepsi Editores, 2002.

_-_-_. Mental health action plan 2013-2020. Geneva: WHO, 2013.

_____. Preventing suicide: a global imperative. Geneva: WHO, 2014.

_-___. World Health Statistics 2018: monitoring health for the SDGs, sustainable development goals. Geneva: WHO, 2018.

\section{Nota}

${ }^{1}$ G. S. Ferreira foi responsável pela concepção e delineamento da pesquisa, coleta e análise dos dados e redaçáo do artigo. A. P. Fajardo foi coorientadora do estudo que deu origem ao artigo, responsável pela estruturação do artigo e pelas revisões do conteúdo. E. D. Mello foi orientadora do estudo, responsável pela concepção e delineamento da pesquisa, análise dos dados e redaçáo e revisão do artigo. 


\section{Abstract}

\section{Possibilities of addressing suicide in the Family Health Strategy}

The paper introduces a study aimed at knowing how health providers from a Family Health Strategy (FHS) service address suicide-related demands. This qualitative research with an interpretative approach was developed through a narrative focus group with health workers of a service located in Porto Alegre, Brazil. The staff's difficulties when working with the suicide topic and the resulting emotional effects were identified. Social vulnerabilities of the territory, suicide as a taboo, the workers' management of suicide-related demands, and the health network inadequacy hamper the work. Feelings of helplessness, guilt and frustration, as well as work-associated stress and overload, were emotional effects identified in the staff. It was concluded that the FHS work has potential for suicide prevention, being critical to strengthen the services network and provide continuing qualification and support to the professionals, aiming to offer the necessary resources to face the difficulties related to working with this topic.

> Keywords: suicide; public health; Family Health Strategy; Collective Health. 